\title{
Una mirada a las entrañas del Estado mexicano
}

\author{
₹ \\ A Look into the Bowels of the Mexican State
}

\author{
KeVyn Simón Delgado \\ Universidad Autónoma de Querétaro \\ México \\ Correo: kevynsimondelgado@hotmail.com \\ https://orcid.org/0000-0002-88| 8-1437 \\ DOI: 10.48/02/hyg.vi56.369
}

Vicente Ovalle, Camilo. [Tiempo suspendido] Una historia de la desaparición forzada en México, 1940-1980, México, Bonilla Artiga Editores, 2019, 359 pp.

Artículo recibido: I I/08/2020

Artículo aceptado: 4/09/2020

Z ntre 1940 y 1980, el Estado posrevolucionario se consolidó; alcanzó una etapa de crecimiento económico como nunca se había vivido en el México independiente. La estabilidad política era notable, sobre todo en comparación con el resto de Latinoamérica. La imagen de México en el exterior era de un país democrático, liberal y hasta progresista. Al interior, el mito de la Revolución mexicana sostenido por la "familia revolucionaria" organizada en el partido hegemónico -el Partido Nacional Revolucionario (PNR), el Partido de la Revolución Mexicana (PRM) y el (PRI) Partido de la Revolución Institucionalizada- era uno de los principales soportes ideológicos del sistema. Y, sin embargo, este retrato de un país "color de rosa" tenía su contraparte. Probablemente, uno de sus rostros más macabros es el de la desaparición 
forzada como práctica institucional contra los opositores al régimen. Éste es el tema principal de [Tiempo suspendido].

A diferencia de lo que se pudiera creer, según el historiador Camilo Vicente Ovalle la desaparición forzada como herramienta de represión política se empezó a utilizar desde la formación del Estado que surge tras la etapa armada de la Revolución. En las décadas de los treinta, cuarenta y cincuenta fue empleada en numerosas ocasiones contra disidentes de izquierda y derecha, en el campo y las urbes, e incluso contra miembros de la disfuncional "familia revolucionaria". Sin embargo, es durante los sesenta, setenta y ochenta cuando esta práctica de aniquilamiento comenzó a sistematizarse y a institucionalizarse en los cuerpos de seguridad del Estado -llámese Ejército y policías-, con el cobijo del poder judicial y los medios de comunicación al servicio del Estado.

Colocadas las piezas (que van de la lucha de Rubén Jaramillo, pasando por el intento de asalto al cuartel militar en Madera en 1965 y las organizaciones populares en Guerrero, hasta llegar a las matanzas en Tlatelolco en 1968 y el "Halconazo" en 1971), se desató el "ciclo de violencia", determinado por la estrategia contrainsurgente. Las armas del gobierno aplastaron al que posteriormente se le nombró como "movimiento armado socialista", en el marco de lo que se empezó a llamar como "guerra sucia" en los setenta; los medios de comunicación al servicio del Estado se encargaron de despolitizar el movimiento, expandiendo la idea de que los militantes "guerrilleros" no eran más que delincuentes, desadaptados sociales deseosos de violencia, antimexicanos contrarios al progreso, a su pueblo y a su historia, agentes manejados desde el extranjero con la ambigua tarea de desestabilizar al país y obstaculizar la llegada de su "grandioso destino". Una vez desmantelados los grupos revolucionarios, arrestados, asesinados o desaparecidos sus militantes, la "historia oficial" buscó borrar aquel episodio. En los ochenta, ni testimonios ni archivos ni libros sobre el tema eran fáciles de conseguir. El silencio al respecto 
era casi total. Durante mucho tiempo no se habló de este proceso como sociedad. Quedaron pendientes la construcción de unas memorias e historias públicas al respecto.

Dos coyunturas abrirán el debate en torno a la luchar armada y la "guerra sucia" implementada por los gobiernos, desde Adolfo López Mateos, Gustavo Díaz Ordaz, Luis Echeverría Álvarez y José López Portillo. La primera se dio con el levantamiento del Ejército Zapatista de Liberación Nacional (EZLN) el 1 de enero de 1994. Aquella jornada, cuando el gobierno de Carlos Salinas de Gortari se congratulaba de entrar al Tratado de Libre Comercio con los Estados Unidos y Canadá, indígenas de Chiapas, esbozados o encapuchados, revivieron la vía armada, en apariencia cerrada desde finales de los setenta. Con todos los reflectores sobre el asunto, se abrió la puerta para investigar sobre el origen del EZln, tema que databa desde los setenta. Por ello, de paso, se indagó en el movimiento armado socialista y, más o menos, sobre la estrategia contrainsurgente. La segunda coyuntura se presentó con la alternancia federal con Vicente Fox Quesada y el Partido Acción Nacional (PAN) en el 2000. La búsqueda de la justicia transicional necesaria hizo que se reabriera el debate sobre los crímenes cometidos en el pasado. Como una medida para investigar al respecto, se abrieron los fondos de las extintas Dirección Federal de Seguridad (DFS) y Dirección General de Investigaciones Políticas y Sociales (DGIPS), organismos protagonistas de la represión de entonces. Los fondos se abrieron en 2002 y fueron censurados, de manera más evidente, a partir de 2014, aunque existe la sospecha de que el encargado de ellos, el exagente de la DFs Vicente Capello, ya los habría "intervenido".

En ese contexto, Camilo Vicente Ovalle empieza a indagar sobre las violencias estatales en Latinoamérica, hasta enfocarse en México, donde, además, lo une una historia familiar: madre y padre del autor -Bertha Alicia Ovalle y Jesús Vicente- fueron víctimas de la contrainsurgencia. Desde entonces, Camilo ha trabajado la violencia política y la represión del Estado contra los 
movimientos sociales opositores, sobre todo durante los años conocidos como "guerra sucia".

Como adelanta el autor, la violencia del Estado mexicano en realidad no ha sido muy estudiada. Por supuesto que el rostro autoritario está presente en muchos textos, especial sobre la matanza de Tlatelolco y, en general, sobre la represión contra el movimiento armado, pero no se ha abordado cuál era la lógica de dicha violencia: ¿Cómo?, ¿dónde? ¿cuándo? y ¿por qué? Preguntas básicas pero elementales, que pocos han intentado responder. Por supuesto, Camilo retoma las obras clásicas que explican el desarrollo del Estado mexicano, de autores como Daniel Cosío Villegas, Lorenzo Meyer, Héctor Aguilar Camín, etc.; así como las investigaciones que abordan a las izquierdas y a las organizaciones político-militares de los sesenta y setenta, de Barry Carr, Laura Castellanos, Rodolfo Gamiño Muñoz, Sergio Arturo Sánchez Parra, etc. Retomando, en buena medida, textos redactados desde los Estados Unidos, que le dan otra dimensión a la estrategia de contrainsurgencia; y revisando artículos periodísticos (de prensa "nacional" y regional) que abordaron las desapariciones forzadas. Aunque, subrayo, el enfoque de Vicente Ovalle es de lo más original, por lo que el diálogo con la historiografía sobre la época es horizontal, sin entablar, me parece, una discusión con alguna obra en particular.

Para esto, primero que nada, Camilo propone otra categoría para renombrar a la siempre entrecomillada y poco clara "guerra sucia". Para él, es más claro definirla por la estrategia: la "contrainsurgencia”. A partir de la cual empezará a dar respuesta a las preguntas señaladas. Y, según explica, este concepto abarca más que la represión dirigida a las organizaciones político-militares. Los grupos y aparatos legales e ilegales del Estado combatieron a todas las disidencias políticas en general, léase campesinas, obreras, estudiantiles, partidistas, etc. Casos que, en numerosas ocasiones, se entrecruzaron con la lucha armada. Además, el marco represivo se expande más allá de las víctimas directas de 
detenciones-desapariciones, ya que la sociedad entera fue víctima de la contrainsurgencia, al ser sometida y engańada por el Estado. Aunque es claro que no se implementó igual contra toda la disidencia, ni en los mismos tiempos ni en todas las regiones del país.

Otras concepciones básicas, como el espacio y tiempo de este proceso, han variado, al no haber un criterio metodológico consensuado ni más exacto. Su "inicio" se ha ubicado desde los levantamientos armados de Jaramillo en los cuarenta, el asesinato del mismo Jaramillo en 1962, el asalto al cuartel militar de Madera en 1965, o desde la matanza de Tlatelolco en 1968. ¿Cuándo termina? Entre los sexenios de López Portillo y De la Madrid Hurtado, con la amnistía del 78, las "últimas" detenciones-desapariciones y la desintegración de la DFS en 1985. Por su parte, Camilo critica esta comprensión del fenómeno en un marco de "fechas extremas", es decir, "aquí inició y acá terminó", buscando, por ejemplo, la primera desaparición forzada o el último preso o asesinato político. La regionalización también es divergente; en Guerrero, Morelos, Chihuahua, Ciudad de México, etc., no en todas las regiones "inicia" y "termina" en la misma fecha. Incluso se baraja la posibilidad de ligar la "guerra sucia" con la "guerra contra el narcotráfico" y expandir, entonces, el periodo de la violencia del Estado, siguiendo "otra guerra sucia", una "segunda guerra sucia" o la continuación de la "primera". Ya que las raíces y ramificaciones de la violencia son vastas.

En lo que a la estrategia contrainsurgente se refiere, Vicente Ovalle ofrece evidencia clara y muy bien sistematizada sobre las desapariciones a manos del Estado. Tomando como base los testimonios de los detenidos-desparecidos de manera temporal, de los sobrevivientes de la contrainsurgencia y de los "archivos de la represión”, es decir, de los fondos de la DFS y la DGIPS. En particular en tres entidades: Oaxaca -de donde es originario y en donde detuvieron a su familia en los setenta por su participación en la Coalición Obrera, Campesina y Estudiantil del Istmo (Cocei)-, Sinaloa y Guerrero. 
El tema y la forma en la que lo aborda tienen mucha importancia porque indaga en los servicios de inteligencia mexicanos y el uso político que le dio el régimen en el contexto de la Guerra Fría, con el anticomunismo y la seguridad interna como base, con los que se justificó la eliminación de la disidencia. Así como en el entrenamiento antiguerrillero y contrainsurgente del Ejército, proporcionado por los Estados Unidos. Es decir, cómo se va construyendo el complejo contrainsurgente. Hay que destacar que el autor considera, y da pruebas, para afirmar que la DFs y el Ejército colaboraron desde un principio en dicha estrategia, revalorando el peso de la disidencia política y el delito de disolución social.

¿En qué consistió la contrainsurgencia? El autor nos describe algunos elementos: cárceles clandestinas que, generalmente, pasaban por el Campo Militar Número 1 en la Ciudad de México, lo que Camilo nombra con acierto como "el circuito de la detención-desaparición”, el cual incluyó tres momentos: aprehensión, detención y definición final; detenidos-desaparecidos temporales y permanentes, cuyos testimonios, recuperados por el autor, nos dan una idea de cómo era la ruta de la desaparición; la "profesionalización" del circuito hasta mejorar la estrategia, que llegó a su pleno entre 1974 y 1978, fechas en las que más personas fueron desaparecidas de manera permanente; la desarticulación de las redes guerrilleras; los "vuelos de la muerte" y la persecución en Guerrero, sobre todo contra el Partido de los Pobres; la Brigada Blanca conformada el 7 de junio de 1976 (que actuó en el Valle de México), cuyo objetivo era exterminar a la Liga Comunista 23 de Septiembre; el papel activo del poder judicial; el inicio de la "guerra contra el narcotráfico" en Sinaloa en 19761977 que le da otro marco a la violencia del Estado, alcanzando a la población civil no confrontada con el Estado; el discurso de la contrainsurgencia y la creación del enemigo, con lo que se "justificaba" su represión; las torturas, muchas veces aplicadas de modo directo por los dirigentes de la DFs; los documentos internos y las palabras clave para nombrar a los detenidos y los 
desaparecidos, hasta llegar al grado de dejar plasmadas ficciones que "explicarían" qué fue de los desaparecidos, haciendo una doble desaparición, tanto física como documental; la negación pública de la propia existencia de las guerrillas, así como de la represión por parte del Estado, etc.

Algo que señala el autor en su introducción y su conclusión, es que dicha obra se ve impactada por las violencias del tiempo presente. La "guerra contra el narcotráfico", los normalistas desaparecidos de Ayotzinapa, etc., le dan otro marco para revisitar las violencias del pasado reciente, de donde provendría, en parte, la violencia actual. Ésta remite a investigar con mayor seriedad la violencia del pasado reciente. Da a entender que los criterios históricos sobre esta estrategia contrainsurgente deberían ser tomados en cuenta por las políticas públicas de hoy, si es que desde éste ámbito se busca fortalecer la memoria, la verdad y la reparación, obviamente poniendo en el centro a las víctimas. Por todos estos elementos, en síntesis, es de lo más importante la obra de Camilo Vicente Ovalle, un texto que, sin duda, será consulta obligada sobre el tema, por las puertas que abre para observar lo más oscuro del Estado mexicano. 厚 